\title{
Description and Pilot Evaluation of a Dreamer Ally Training for Higher Education Staff and Faculty
}

\author{
Ellen Hawley McWhirter \\ Kristin Elizabeth Yarris \\ Bryan Ovidio Rojas-Araúz
}

University of Oregon

\begin{abstract}
We describe a Dreamer Ally training provided to staff and faculty on a university campus and present results of a pilot evaluation of this training. The Dreamer Ally training was designed to (a) increase university faculty and staff awareness, understanding, and self-efficacy for working with Dreamer students and (b) stimulate action to make the campus more responsive to the challenges and contributions of Dreamer students. For the purpose of this study we define Dreamer students as inclusive of undocumented students, students with the temporary protection of DACA (Deferred Action for Childhood Arrivals), students who qualify for the state's tuition equity program, and students from mixed legal status families. Study goals were to describe the training, gather pilot data on participant learning goals, post-training satisfaction and self-efficacy for supporting Dreamer students, and generate participant feedback about utility of training components and their plans for subsequent action. Participants completed questionnaires before and after the training. Responses to open-ended questions indicated that most participants attended in order to learn how to better support Dreamer students. Paired samples (pre and post) t-tests indicated significantly higher self-efficacy for supporting Dreamer students at posttest. Participant satisfaction with the training was high and they found the information session content and working through different Dreamer student scenarios most useful. Action plans included changing program or unit websites to be more inclusive of Dreamers. Limitations include the absence of a control group. Findings can inform institutional efforts to raise faculty and staff awareness of and responsiveness to the challenges facing Dreamer students.
\end{abstract}

Keywords: Dreamer; undocumented students; ally training; self-efficacy.

(C) 2021 McWhirter, Yarris, \& Rojas-Araúz. Free to copy and share for education and scholarship under a Creative Commons Attribution NonCommercial-NoDerivatives 4.0 License. 
Approximately 98,000 undocumented students graduate from U.S. high schools each year (Zong \& Batalova, 2019). Only about 26\% matriculate into higher education (Warren \& Warren, 2013) and even fewer complete their degrees. Barriers and stressors that undocumented college students encounter include lack of funds, limited legal work options, discrimination, transportation (ineligibility for drivers' licenses in some states, inability to leave the country for educational or familial reasons), and mental health challenges such as depression, anxiety, and fear associated with potential discovery of their status or that of their family members, arrest, and deportation to a country that is not home (Abrego \& Gonzalez, 2010; Suárez-Orozco, et al., 2015).

Compounding the issues faced by undocumented college students is a rise in national anti-immigrant rhetoric that is disparaging and punitive of people who are in the country without authorization (Gemignani \& Hernandez-Albujar, 2015; Pierce et al., 2018). Even students with the temporary protection of the Deferred Action for Childhood Arrival (DACA) program experience significant fear and anxiety (Suárez-Orozco et al., 2015), particularly since the 2017 attempt to rescind this program (Pierce et al., 2018; Pierce \& Selee, 2017) and continuing uncertainty about its future (Department of Homeland Security [DHS], 2020). DACA offers a temporary legal status to qualified applicants such that they can work and/or to attend college for a two-year period, though it is not a pathway to citizenship. Applying for DACA requires providing personal information that could be used to find and deport the applicant or their family members. The attempt to end DACA has been accompanied by other policy changes hostile toward immigrants, such as efforts to eliminate Temporary Protected Status (TPS; U.S. Citizenship \& Immigration Services, n.d.) protection for refugees from Honduras and El Salvador, failure to enact comprehensive immigration reform, and the indefinite holding of asylumseeking, unaccompanied children and families in detention centers across the U.S. (Dash, 2020; Muñoz et al., 2018; Pierce, 2019). Such rhetoric and policies adversely affect undocumented, refugee, and immigrant students and their parents, for example, raising financial barriers, diminishing hopes of attending college, severely constricting opportunities, reducing available support resources, and creating barriers to belonging and integration (Gurrola et al., 2016; McHugh, 2018; Roche et al., 2018).

Many college and university campuses are engaged in actions to attract, support, and retain undocumented college students. College-based initiatives are key to the immediate and longer-term academic success and wellbeing of undocumented students (Caicedo, 2019; Gonzales, 2016). To succeed, these efforts must attend to the many contextual constraints such students encounter, including high rates of unfair or negative treatment by faculty and staff (Suárez-Orozco et al., 2015). Suárez-Orozco, Katsiafikas et al. (2015) described an ecological model of "undocu-friendly" campuses, characterized by efforts to: 1) understand undocumented students' experiences and challenges and educate service providers on campus, 2) provide support-academic advising, mental health counseling, guidance about financial aid, and offering safe spaces, and 3) public and official endorsement of undocumented students.

A growing number of studies have focused on the experiences of undocumented college students and provided suggestions for how to support them (see review by Bjorkland, 2018; Yasuike, 2019). In addition, there is evidence that universities can enact policies and practices that improve the experience of undocumented students (e.g., Enriquez et al., 2019; Valenzuela et al., 2015). Effective transformation of campus climates to "undocu-friendly" sites requires a clear stance from university leadership as well as developing, "... a cadre of allies to work toward transforming passive indifference or regressive attitudes so that long-term widespread support for undocumented students' educational access and attainment is realized" (p. 3, Barnhardt et al., 2017). In spite of calls to enhance university faculty and staff responsiveness to the concerns of undocumented students, there is scant empirical research on interventions aiming to do so.

In what follows, we review the literature on training allies of undocumented college students. We describe the context in which we developed a training intervention designed to create such a 'cadre of allies' among staff and faculty, the conceptual model framing our efforts, and the targets of our intervention. We describe the 
training itself and an evaluation of the training. Our specific study aims are to describe the development and components of the training, and to present feedback from participants that sheds light on their goals for seeking the training, elements they found most helpful, and their plans for subsequent action to support undocumented students. We also present data on participants' self-efficacy for supporting Dreamer students before and after the training. First, we clarify terminology.

For the purpose of this study, we use the operational definition of "Dreamer" students that we have employed on our campus, which is inclusive of undocumented students, students with the temporary protection of DACA ("DACAmented"), students who qualify for the state's tuition equity program (which grants in-state tuition to undocumented students who meet specific criteria), and students from mixed legal status families. Such students share many challenges related to immigration-related stressors, anxiety, and uncertainty, albeit with differential access to resources based on immigration status (Abrego, 2019). It is important to note that our encompassing use of the term 'Dreamer' was derived from conversations with undocumented and DACAmented students on our campus, but this term is not universally preferred or employed consistently in the literature. By allies, we refer to individuals who work from positions of relative power, privilege, and resources vis-à-vis the impacted community (in this case, Dreamer students) to provide empathy and concrete supports to facilitate that community's success and well-being (Broido, 2000).

\section{Training Dreamer Allies}

Numerous university campuses implement trainings to foster allyship with undocumented students, as evidenced by the links to campus events across the country that we generated in a cursory search for "undocumented student ally training." The effect of such trainings remains an open question, however, because empirical studies of such interventions remain scarce. We used varied combinations of the keywords "undocumented" "college student" "ally" "training" and "workshop" to search for peer reviewed journal articles in the following databases: Proquest Education Data Base, Social Science Database, and Psychology Behavioral Science Collection. We also searched using Google Scholar. Our search yielded one study describing the development of the "DREAMzone" workshop (Cisneros \& Lopez, 2016) and four studies that assessed outcomes of trainings designed to increase campus support for undocumented students.

Three of the intervention studies evaluated outcomes associated with the Arizona-based DREAMzone ally training. First, Cadenas and colleagues used an experimental research design to test the effectiveness of DREAMzone and an alternative intervention on changing faculty, staff and student attitudes towards undocumented immigrants at a university campus (Cadenas et al., 2016). Participants were assigned to a control group, to the four-hour DREAMzone training that includes a panel of undocumented university students and activities for enhancing supports, or to a 30-minute documentary film featuring the stories of five undocumented students. Participants in both intervention groups demonstrated increased empathy and reductions in prejudice and anxiety toward undocumented immigrants, relative to the control group, with greater changes in empathy and prejudice reduction among DREAMzone workshop participants relative to participants viewing the film (Cadenas et al., 2016). In a subsequent study, Cisneros and Cadenas (2017) demonstrated that participation in a DREAMzone training resulted in greater faculty and staff knowledge and self-efficacy for working with undocumented students. Most recently, a longitudinal qualitative study assessed higher education professionals' awareness, knowledge, skills, and self-efficacy for responding to the concerns of undocumented students after participating in the DREAMzone intervention (Cisneros \& Lopez, 2020). Findings from analysis of 2-month and 8-month post-intervention responses suggested that participants felt greater empathy for undocumented students, as well as confidence in their ability to support and advocate for them. Combined, these studies suggest that the DREAMzone ally training has the potential to change attitudes, knowledge, and agency for supporting undocumented students. 
In the fourth study, Chen and Rhoads (2016) explored possibilities for a university ally training program to lead to institutional changes. Using semi-structured interviews, the authors assessed the impact of an undocually training on faculty and staff 'critical consciousness', which they defined as awareness of undocumented students' realities. Further, the authors explored participants' abilities to engage in "transformative resistance," fostering more inclusive policies and practices at the institutional (university) level towards undocumented students (Chen \& Rhoads, 2016). Themes generated from the interviews were: one, student activism is important to raising allies' awareness and empathy towards student needs and struggles; two, the university context itself produced contradictions vis-à-vis undocumented students-offering support but within a constrained climate; three, working alongside students, allies were able to successfully institutionalize supports (such as tuition assistance and student advising); and four, developing community networks expands the resources available for undocumented students.

Findings from these four empirical studies suggest that brief interventions can enhance empathy and faculty and staff confidence in their ability to support undocumented students. Further, these findings suggest that collaborative efforts by allies and undocumented students can foster more supportive and inclusive campus, community, and political institutional climates. This is promising, but it is clear that additional research is needed to explore a broader set of ally interventions, particularly given variation in institutional and regional dynamics, policies, and administrative stances (Mwangi et al., 2019). Cisneros and Lopez (2020) called for evaluations of ally trainings developed in various state, local, and institution-specific climates in order to shed light on the development and impact of interventions within particular ecologies, and create a stronger evidence base for what works. For this reason, we next provide brief information about the particular context of our training intervention.

\section{Contextual Considerations}

The effects of national policies on local attitudes toward immigrants varies across state and institutional contexts, in part as a function of demographic, sociohistorical, economic, and political characteristics (McHugh, 2018; Nájera, 2020). State dynamics in turn shape and constrain public university supports for undocumented students. Some characteristics of the context in which our intervention was developed include that this is a predominantly White institution ( $85 \%$ of staff, $86 \%$ of faculty, and $59 \%$ of students) in a predominantly White state (75\%) (U.S. Census Bureau, 2019), with a rapidly growing Latinx population. In 2016, 22\% of K-12 students in the state were Latinx/Latino/a (U.S. Census Bureau, 2017), and an estimated 7.5\% of K-12 students had at least one undocumented parent (Capps, Fix, \& Jong, 2016). Of undocumented immigrants in the state, $82 \%$ are of Mexican or Central American origin. The state legislature has sought to increase access to higher education for undocumented students, for example, by offering in-state tuition for undocumented high school graduates who meet qualifying criteria, passage of a 2018 bill extending in-state tuition for students with non-renewed DACA permits, and the extension of tuition equity to qualifying graduate students in 2019. Nearly 10,000 people in the state have applied for DACA status since 2012 (Center for American Progress, 2019). Overall our context can be described in terms of immigrant-inclusive state policies, and low levels of ethnic diversity among students, faculty, and staff at our institution. Generally, Dreamer students on our campus keep a low profile and have chosen not to be as collectively-visible as Dreamer students at university campuses in California or Texas, for instance.

\section{Conceptual Framework and Intervention Targets}

The broad conceptual framework for this study is an ecological model (Bronfenbrenner, 1979), which has been employed by other scholars to capture the varied levels at which transformative change is important in supporting undocumented college students (Nájera, 2020; Suárez-Orozco et al., 2015). Examples of changes beneficial to Dreamer students at different levels of a campus ecology could include reducing microaggressions 
and increasing empathy from peers, staff, and faculty (microsystem), increasing availability of institutional web-based resources for the families of Dreamers to better navigate higher education (mesosystem), removing citizenship criteria from scholarships (exosystem), and consistent, visible messages of support and inclusion from the administration (macrosystem).

Consistent with this conceptual model, and in line with efforts and recommendations by Cisneros and colleagues, we sought to enhance staff and faculty awareness and empathy regarding the challenges faced by Dreamer students, and increase their knowledge and skills for supporting Dreamers, in terms of helpful (and unhelpful) responses and behaviors, as well as through learning about available resources. The definition of an ally of undocumented students used by one national organization (TheDream.US, n.d.) includes knowledge, awareness, and skills along with committed action that addresses multiple facets of the campus (e.g., barriers, resources, practices). Committed actions may target individual, departmental, and institutional levels of change. But knowledge, awareness, and skills are not always sufficient to support behavior change. In order to support the translation of knowledge and awareness into committed action, we also aimed to enhance staff and faculty self-efficacy for supporting Dreamer students.

Self-efficacy expectations are beliefs about one's ability to carry out domain-specific tasks (Bandura, 1986). Self-efficacy expectations influence an individual's likelihood of attempting a behavior, and persistence in that behavior in the face of difficulties (Bandura, 1986). For example, a person with greater self-efficacy for supporting Dreamer students will be more likely to take action to support students (e.g., identify themselves as an Ally, refer the student to campus resources, advocate for systemic change) and to persist in the face of challenges (e.g., resistance to support for Dreamers, limited resources for supporting students). Faculty and staff failure to engage with and support undocumented students has been attributed to a lack of self-efficacy for doing so (Canedo Sanchez \& So, 2015). Consistent with Cisneros and colleagues (Cisneros \& Cadenas, 2017; Cisneros \& Lopez, 2020), therefore, we sought to raise self-efficacy for supporting Dreamer students, in order to increase the likelihood that staff and faculty would take committed action.

\section{Study Purpose and Research Questions}

The first goal of this study was to describe the development and nature of our Dreamer Ally training for faculty and staff (including graduate students with instructor, teaching assistant, counselor, and advisor roles). We did not include undergraduate students in the ally training in order to focus more specifically on ally behavior in roles with authority relative to undocumented students. In addition, we sought to answer the following questions: 1) What were participants' goals for the training? 2) Did participant self-efficacy for supporting Dreamer students increase after participation in the Dreamer Ally training (hereafter, Ally training)? 3) How satisfied were participants with the Ally training? 4) What did participants find most useful, and what suggestions did they have for improvement of the training? Finally, 5) What actions did participants commit to taking in order to support Dreamer students on campus? We hypothesized that participants completing the Ally training would have higher self-efficacy for understanding challenges and barriers faced by Dreamer students, referring Dreamers to appropriate resources, knowing how to respond if ICE comes to campus, and for carrying out their Ally action plans, relative to their pre-training self-efficacy. The remaining aims are descriptive and as such have no associated hypotheses.

\section{Methods}

\section{Participants}

The Dreamer Ally training was held at a large public university. A total of 253 participants completed the pre-training survey and 173 completed the post training survey. Demographic descriptors are reported for those completing the post-test, as not all of those completing the pretest attended the training. Participants self- 
reported their roles as university staff (61\%), faculty (26\%), graduate student employees (e.g., instructors, TAs, or student services providers, $7.5 \%)$ and other (5.2\%). Staff members were from units across the university such as the university counseling center, academic advising, the career center, financial aid, admissions, and academic departments (e.g., program assistants and student services coordinators); as such, staff members held a wide variety of roles and responsibilities with students. Participants tended to be newer employees; $56 \%$ had worked at the university for 0-5 years, 20\% from $6-10$ years, and 24\% for more than 10 years. Reported age ranges were 21-29 (19.2\%), 30-45 (52.3\%), and 46 or older (28.5\%). Of these 173, pre and post surveys could be matched for 133 participants. No other demographic data was collected.

\section{Procedures}

Four Ally trainings were implemented in AY 2017-18, three of which were campus-wide and one that was restricted to the college of arts and sciences. Notice of each training was distributed over university email via college, department, and student service unit listservs. Participation in the training was voluntary, with faculty and staff completing the training as part of their (paid) work time. Participants pre-registered to reserve a spot in the training, and all four trainings filled within days of being announced. For each training, there were a handful of last-minute cancellations. Those registered received an email approximately one week prior to the training requesting that they complete the pre-training survey. Upon check-in the day of the training, participants who had not completed the survey were invited to do so on their phones using a tinyurl. After the workshop was completed, within 24 hours participants received a link to the follow-up survey. A follow up email requesting survey completion was sent 3 times over the next 10 days.

Participants responded to a series of questions in order to generate a unique ID code that was used to match pre and post surveys (e.g., first letter of your mother's name or the person most like a mother to you, last digit of your cell phone number). No demographic or other personally-identifiable information was collected beyond that reported in the participant section, in order to meet the standard for exempt status, which was granted by our University IRB.

University support for the trainings was provided from multiple sources including the institution's offices for diversity and equity, international affairs, and the office of the president. This support covered costs such as a box lunch for each participant, campus space in which to hold the trainings, supplies (e.g., handouts, Ally placards) and administrative support.

\section{Development and Content of the Ally Training Intervention}

The Dreamers Working Group (DWG) at our institution formed in 2014 in response to growing numbers of Dreamer students and the desire to ensure the retention, academic success, and overall wellbeing of these students. The DWG consists of faculty, staff, and Dreamer students who come together on a voluntary basis to make our institution more "undocu-friendly" by raising awareness of the challenges and realities of Dreamer students, increasing support services for Dreamer students, and using institutional resources to advocate for policy changes to improve the lives of Dreamer students (Suárez-Orozco et al., 2015; United We Dream, n.d.). Members of the DWG include the authors, and are from a range of units (e.g., faculty and student affiliations include international studies, education, counseling psychology, political science, and anthropology; staff affiliations include the multicultural center, admissions, division of equity and inclusion, student advising, and the counseling and career centers). Consistent with our mission, in the fall of 2014 the first author developed a presentation on undocumented college students for the campus career center. This became the basis for the one-hour DWG "information session" that we continue to offer to campus and community units upon request. The information sessions contribute to campus knowledge and awareness, but we did not view these as sufficient to foster the skills, self-efficacy, and committed action that define allies. 
In 2015-16 the DWG developed the ally training evaluated in the present study. The four-hour intervention was modeled in part on similar undocu-ally training programs implemented at several California State University and University of California campuses (e.g., http://web.csulb.edu/divisions/students/ dream/ advocacy/ally.html), which had in turn been based on queer ally trainings implemented on college and university campuses in the 1990s (e.g., Evans \& Wall, 1991). The contents of the intervention were also informed by the literature on undocumented students and by interviews conducted with undocumented, DACAmented, and mixed status students on campuses in our region by a student member of the DWG for her MA thesis (Cebreros, 2016). The training is delivered by members of the DWG, typically with 5 or 6 members actively delivering content, and an additional DWG member sitting at each table in the room to facilitate small group conversations. All three authors were involved in the development and implementation of the training, including the third author, a formerly undocumented immigrant from Central America, DREAM activist, and doctoral student.

Contents of the Ally Training include, in chronological order, introductions and aims of the DWG, empathy building, an information session, presentation of legal information, Dreamer scenarios, and developing action plans. See Figure 1 for a visual summary of the training components. The empathy building section opens with either a short video of a first-person narrative of a Dreamer's transition to college or an inperson account of a Dreamer student on our campus. Participants then read short paragraphs that describe typical Dreamers' experiences and engage in small group discussion. For example, one paragraph described a young person becoming aware of their undocumented status when attempting to obtain a driver's license. We encouraged participants to reflect on these situations from an emotional standpoint, asking them to consider "How would that make you feel?" The opportunity to learn about such stressors and connect emotionally with these experiences, developing social empathy, may increase the likelihood of committed actions in support of Dreamer students (Segal \& Wagaman, 2017).

\section{Figure 1. Dreamer Ally Training}

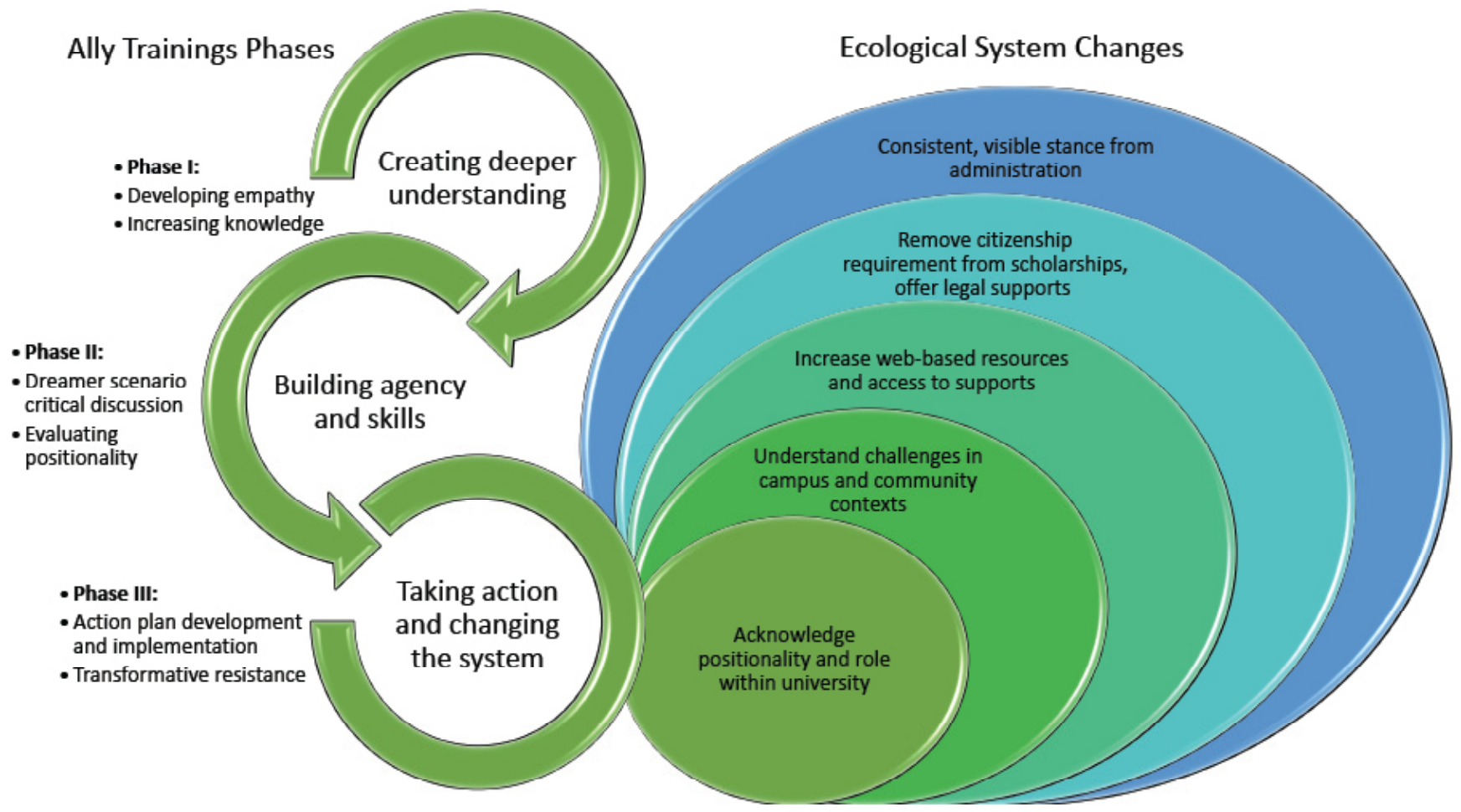


The information session developed in 2014 and continuously updated by the DWG is the next part of the Ally Training. Delivered by power point, this portion of the intervention reviews terminology (e.g., mixed status, DACAmented, and undocumented), relevant federal legislation such as the DREAM Act and DACA, state tuition equity legislation and sanctuary policies, and existing university resources for Dreamer students, such as financial aid, scholarships, mental health supports, and academic advising.

The legal information section is presented by the university General Counsel. This ten-minute session focuses on legal rights and recommended steps to take should faculty or staff encounter ICE on campus. The empathy-building and information sharing sessions comprise Phase I of the Ally Training, as indicated in Figure 1.

The scenario component of the training consists of a small group discussion in which participants work at their tables to engage with a real-world situation faced by a Dreamer student, and discuss and evaluate possible faculty or staff responses. In order to enhance the discussion and application of training content, table seating is arranged in advance and organized by participant unit or department (e.g., career center staff, or faculty and staff in the same department). The scenarios were derived from actual experiences of Dreamer students on our campus and similar campuses (Cebreros, 2016). For example, in one scenario a student learns from a staff member that the major they enrolled in requires legal documentation; in another scenario, a faculty member encourages all students to study abroad, alienating an undocumented student who is unable to do so. For 15 minutes, participants share responses to, "What was the intention of the faculty/staff?" and then "How could the faculty / staff have done this differently?" Next, each small group reports their responses to the large group. Then the DWG presents best practices in fostering undocu-friendly college and university campuses, using resources derived from scholarly literature (e.g., Suárez-Orozco, Katsiafikas et al., 2015) and a number of national organizations (e.g., Educators for Fair Consideration, now called "Immigrants Rising: Transforming Lives through Education", and United We Dream). Example practices include displaying support for Dreamer students and expanding access to scholarships and financial aid. These activities, Phase II of the training, aim to build skills and self-efficacy.

In the final section of the training (Phase III), over a working lunch, participants develop action plans for supporting Dreamers and discuss the plans with those at their table. Participants are invited to sign Ally contracts expressing their commitment to support Dreamer students. In this way, the training seeks to translate individual-level changes in self-efficacy into unit- and institutional-level changes that make the university more supportive and inclusive of Dreamer students ("undocu-friendly"). Participants turn in their Ally action plans to DWG members at the conclusion of the training, which are scanned and returned, along with DREAMER ALLY placards and buttons, via campus mail. Note that because action plans were not de-identified, the scanned pledges were not included as data for this study. Instead, we analyzed participant action plan descriptions, provided via the anonymous follow up survey.

\section{Measures}

Demographic questions. Participants selected from a menu of options to indicate their age range, role at the university (faculty, staff, or graduate assistant), and number of years (range) at the university.

Self-efficacy for supporting Dreamer students. Competencies for working with undocumented students include awareness of undocumented student needs and assets, knowledge of academic, legal, and personal experiences facing Dreamers, and ability to connect Dreamers with appropriate resources and advocate with and for Dreamer students (Cisneros \& Cadenas, 2017; Neinhusser \& Espino, 2018). Based on such competencies and the content of our training, the first author developed five items to assess participants' perceived capability in their awareness, knowledge, or skills related to working with Dreamer students (e.g., 
know what to do if ICE comes to campus). We followed Bandura's (2001) recommendations for developing selfefficacy items. Likert-type response options ranged from 1 (Not at all Confident) to 5 (Very Confident). Items were analyzed separately.

Satisfaction with training. Five items were developed for the purpose of this study assessing satisfaction with the training with respect to content, clarity of information, pace, helpfulness, and structure, using a scale ranging from 1 (Not at all Satisfied) to 4 (Very Satisfied).

Open ended questions. Prior to the training, participants responded to "What do you hope to get out of this training?" At post-test, participants responded the following questions: "What part of the Ally Training did you find most helpful?", "Are there any suggestions for improvement you'd like to share?", and "Please briefly describe your pledge or action plan."

\section{Data Analysis}

Thematic content analysis was used to analyze responses to the four open-ended questions (Braun \& Clarke, 2006). We made the assumption that the data reflects the realities of participants and analyzed the data at the explicit level. Our goal was to provide a thorough description that captured the breadth of participant responses rather than to minimize the number of themes (Braun \& Clarke, 2006). The first and second authors conducted the qualitative data analysis. Prior to analyses we discussed potential influences and biases associated with our positionality as White female academics engaged in scholarship, teaching, and service focused on Latinx communities, and as members of the DWG. Following the same process for each open-ended question, we first independently read responses, attending to patterns and generating an initial list of codes. Next, we came to mutual agreement on an initial list of codes and independently coded the responses for 20 entries. We then discussed our coding of this initial subset of questions and remedied any discrepancies by clarifying the scope of each code or creating more inclusive definitions. After agreeing upon a master list of codes for each question, we then independently coded the remaining participant responses. Each response could receive more than one code. Next, we compared coding results, identified discrepancies, and came to consensus on final coding. Finally, we organized the codes into themes. Given our aim to describe the breadth of participant responses, we did not limit themes by prevalence of content. We repeated this process for each question sequentially.

\section{Results}

\section{"What do you hope to get out of this training?"}

As indicated in Table 1, the most frequent of the three themes was to support students. For example, one participant wrote, "I hope to be able to stand for Dreamers and to help them achieve their goals. I want to remove barriers that hinder their progress and their growth." Another offered: "I both teach and serve as my department's undergraduate advisor. I seek an understanding of the challenges facing students who face the risk of possible deportation for themselves, friends, or family." The second theme, "Gain Knowledge" is illustrated by the following: "To gain a better understanding of the current issues and challenges facing Dreamer students, ... [and] tools and resources to be a strong ally." Finally, a smaller set of responses were coded as "To Learn the (university) position towards undocumented students", such as "To understand what my legal responsibilities are if ICE comes to campus and how to respond." 
Table 1. Themes Derived from Open-Ended Questions

\begin{tabular}{|c|c|c|}
\hline & $n$ & $\begin{array}{l}\% \\
\text { within } \\
\text { question }\end{array}$ \\
\hline \multicolumn{3}{|l|}{ Question 1: What do you want to get out of this training? } \\
\hline \multicolumn{3}{|l|}{206 participants respond, 1-3 Themes assigned per respondent, $M=1.9 s d=.61$} \\
\hline $\begin{array}{l}\text { Theme 1: Better Support Students (gain confidence, be better at supporting students, be } \\
\text { better prepared, be an advocate for students) }\end{array}$ & 186 & 48.2 \\
\hline \multicolumn{3}{|l|}{$\begin{array}{l}\text { Example: "I hope to gain a lot of information about the challenges and barriers that } \\
\text { Dreamer students face and how to best support them." (coded as } 2 \text { also) }\end{array}$} \\
\hline \multicolumn{3}{|l|}{ Example: "How I can support Dreamers achieve their academic and career goals" } \\
\hline Theme 2: Gain Knowledge (information, resources, understanding of issues) & 163 & 42.2 \\
\hline \multicolumn{3}{|l|}{$\begin{array}{l}\text { Example: "I seek an understanding of the challenges facing students who face the risk of } \\
\text { possible deportation for themselves, friends, or family." }\end{array}$} \\
\hline \multicolumn{3}{|l|}{$\begin{array}{l}\text { Example: "I also would love to have more clarity on financial challenges that Dreamers } \\
\text { face and specific financial resources and scholarships available to Dreamer students." }\end{array}$} \\
\hline $\begin{array}{l}\text { Theme 3: Know University Stance (understand university stance, legal issues, what to do if } \\
\text { ICE comes to campus, to be able to act within bounds of work responsibilities) }\end{array}$ & 37 & 10.0 \\
\hline \multicolumn{3}{|l|}{$\begin{array}{l}\text { Example: "A deeper understanding of what the (school) is doing, and what individual } \\
\text { units can do, to support Dreamer students." }\end{array}$} \\
\hline \multicolumn{3}{|l|}{$\begin{array}{l}\text { Example: "Would like to know campus resources as well as overall support DREAMers } \\
\text { might expect from official campus representatives." }\end{array}$} \\
\hline \multicolumn{3}{|c|}{$\begin{array}{c}\text { Question } 2 \text { (post-intervention): What suggestions do you have for us to improve the training? } \\
101 \text { participants respond, } 1-2 \text { Themes assigned per respondent, } M=1.2 s d=.37\end{array}$} \\
\hline Theme 1: Specific suggestions regarding details of training & 36 & 31 \\
\hline $\begin{array}{l}\text { Example: "When presenter X was presenting, it was hard to follow because what she } \\
\text { was saying was not on the slides." }\end{array}$ & & \\
\hline Theme 2: No change, no suggestions, only compliments & 29 & 25 \\
\hline \multicolumn{3}{|l|}{ Example: "I have nothing but positive things to say. Thank you." } \\
\hline $\begin{array}{l}\text { Theme 3: More time (Move more slowly through material, more networking time, time for } \\
\text { action plans) }\end{array}$ & 21 & 17.9 \\
\hline \multicolumn{3}{|l|}{$\begin{array}{l}\text { Example: "It would be great if we had more time to network with people outside our } \\
\text { department and not just in our own department." }\end{array}$} \\
\hline Example: "I felt rushed and didn't have enough time to develop and share my plan." & & \\
\hline
\end{tabular}




\begin{tabular}{|c|c|c|}
\hline $\begin{array}{l}\text { Theme 4: More attention to resources on and off campus (for both students and their } \\
\text { families) } \\
\text { Example: "Printed information that we could give students who need answers quickly." }\end{array}$ & 10 & 8.5 \\
\hline $\begin{array}{l}\text { Theme 5: Changes to light, audio, technology } \\
\text { Example: "The main speaker was too loud into the microphone." }\end{array}$ & 8 & 6.8 \\
\hline $\begin{array}{l}\text { Theme 6: More UO Dreamer student voices } \\
\text { Example: "One or more additional student examples via video and follow-up discussion } \\
\text { on real-life experiences would be great" }\end{array}$ & 7 & 6.0 \\
\hline $\begin{array}{l}\text { Theme 7: Less time } \\
\qquad \text { Example: "Too much time was spent on the scenarios" }\end{array}$ & 6 & 5.1 \\
\hline \multicolumn{3}{|l|}{$\begin{array}{l}\text { Question 3: What part of the Ally Training did you find most helpful? } \\
145 \text { participants respond, 1-4 Themes assigned per respondent, } M=1.8 s d=.85 \text { ) }\end{array}$} \\
\hline $\begin{array}{l}\text { Theme 1: Information Session (includes any specific information shared during this } \\
\text { portion of training) } \\
\text { Example: "The information session was very helpful." } \\
\text { Example: "The information dump section after the initial discussion about the emotional } \\
\text { impact of Dreamer status was incredibly helpful context." }\end{array}$ & 54 & 21 \\
\hline $\begin{array}{l}\text { Theme 2: Scenario portion of training; ways to handle "situations" } \\
\text { Example: "The small group work around scenarios." }\end{array}$ & 36 & 14 \\
\hline $\begin{array}{l}\text { Theme 3: The process and/or structure of how the training was conducted } \\
\text { Example: "It was a nice balance of objective facts and time to consider the affective } \\
\text { result of policies." }\end{array}$ & 29 & 11.2 \\
\hline $\begin{array}{l}\text { Example: "It was one of the best trainings I've been to on campus - well thought out and } \\
\text { informative." }\end{array}$ & & \\
\hline $\begin{array}{l}\text { Theme 4: Small Group Work (includes discussing topics and issues in small groups at } \\
\text { tables, developing responses) }\end{array}$ & 28 & 10.9 \\
\hline $\begin{array}{l}\text { Example: "I appreciated the table discussions and hearing the other tables ideas. This } \\
\text { was a much better way to focus on the information" }\end{array}$ & & \\
\hline $\begin{array}{l}\text { Theme 5: General Counsel (includes how to respond if ICE comes to campus) } \\
\text { Example: "It was very helpful to hear from the GC as well. I think it was essential that } \\
\text { he made an appearance." }\end{array}$ & 28 & 10.9 \\
\hline $\begin{array}{l}\text { Theme 6: Learning about University and community resources and supports } \\
\text { Example: "Learning about resources on campus." }\end{array}$ & 24 & 9.3 \\
\hline $\begin{array}{l}\text { Theme 7: Empathy Exercises } \\
\text { Example: "I found the exercises which helped me understand the emotional impact on } \\
\text { the students very informative." }\end{array}$ & 15 & 5.8 \\
\hline
\end{tabular}




\begin{tabular}{|c|c|c|}
\hline $\begin{array}{l}\text { Theme 8: Action Planning (brainstorming actions, developing pledges) } \\
\text { Example: "Most helpful was understanding the actions I can take. Now I feel like I can } \\
\text { do something." }\end{array}$ & 13 & 5 \\
\hline $\begin{array}{l}\text { Theme 9: Learning (overall statements of "everything", or general statement about } \\
\text { "learning" at training.) } \\
\text { Example: "I'd really have to say 'all of it'?" }\end{array}$ & 10 & 3.9 \\
\hline $\begin{array}{l}\text { Theme 10: Hearing Dreamer student voices (this includes "videos"; hearing from } \\
\text { Dreamer students within or outside of our institution) } \\
\text { Example: "The video of a Berkeley DREAMer student and hearing stories from } \\
\text { DREAMer students to better understand their experiences and challenges." }\end{array}$ & 10 & 3.9 \\
\hline $\begin{array}{l}\text { Theme } 11 \text { Networking (statements about meeting or connecting with campus colleagues) } \\
\text { Example: "What I liked about this training was coming together with others around } \\
\text { how to support DREAMer students." }\end{array}$ & 7 & 2.7 \\
\hline $\begin{array}{l}\text { Theme 12: Handouts (refers to any handout other than informational session slides, which } \\
\text { are coded in Theme 1) } \\
\text { Example: "The DACA Fact Sheet" }\end{array}$ & 4 & 1.6 \\
\hline $\begin{array}{l}\text { Question 4: Please describe your pledge or action plan } \\
116 \text { participants respond, } 1-5 \text { Themes assigned per respondent, } M=1.8 s d=.71\end{array}$ & & \\
\hline $\begin{array}{l}\text { Theme 1: Share information with colleagues } \\
\text { Example: "I am going to encourage colleagues to participate in training." } \\
\text { Example: "Share the resources from this workshop at an upcoming staff meeting." }\end{array}$ & 59 & 28.1 \\
\hline $\begin{array}{l}\text { Theme 2: Remove barriers to inclusion for Dreamers in my unit/ program (including } \\
\text { admission to program, website and syllabus language, and via diversity committees and unit } \\
\text { diversity action plans). } \\
\text { Example: "I will speak with my department about adjusting background checks to } \\
\text { not include social security numbers or making adjustments that would allow for } \\
\text { undocumented students to work in the department." } \\
\text { Example: "Mypledge is to use my role in our unit Diversity Action Committee to support } \\
\text { DREAMer students." }\end{array}$ & 57 & 27.1 \\
\hline $\begin{array}{l}\text { Theme 3: Display ally status publicly } \\
\text { Example: "I will use ally-focused language in my email signature and syllabus." }\end{array}$ & 48 & 22.9 \\
\hline $\begin{array}{l}\text { Theme 4: Remove barriers in scholarships/financial aid } \\
\text { Example: "Reviewing our scholarships and thinking about universal design in how } \\
\text { we address students and the information we provide." } \\
\text { Example: "Make sure scholarships are as accessible as possible to students who can't fill } \\
\text { out the FAFSA." }\end{array}$ & 20 & 9.5 \\
\hline
\end{tabular}




\begin{tabular}{|c|c|c|}
\hline $\begin{array}{l}\text { Theme 5: Learn more about related issues and resources } \\
\text { Example: "I pledge to continue to educate myself on the politics surrounding this } \\
\text { situation and keep up to date with resources available for Dreamers." }\end{array}$ & 10 & 4.8 \\
\hline $\begin{array}{l}\text { Theme 6: Share General Counsel information } \\
\text { Example: "To support the training of our staff teams about their role if an ICE officer } \\
\text { were to come to their building." }\end{array}$ & 8 & 3.8 \\
\hline $\begin{array}{l}\text { Theme 7: Join DWG } \\
\text { Example: "I pledge to join the Dreamer Working Group." }\end{array}$ & 8 & 3.8 \\
\hline
\end{tabular}

Notes. $n=$ number of responses with coded with this theme, rather than the number of participants who had a response with specific theme. $\%=$ percentage within the specific theme; due to multiple possible codes these do not add to $100 \%$. Each participant response was coded with 1-5 themes, see details within each question.

\section{Self-Efficacy}

Quantitative data were analyzed using SPSS version 25. Means and standard deviations of the five selfefficacy (pre and post training) items for the 133 participant responses that could be matched are provided in Table 2. Results of paired samples t-tests show that participants rated their self-efficacy significantly higher at post-training on all five items. We also conducted two one-way analyses of variance (ANOVAs) to compare, first, pre-test confidence between those who did and did not have matched confidence scores, and second, post-test self-efficacy for those who did and did not have matched scores. There were no significant differences $(p<.10)$.

Table 2. Paired Samples Test Pre and Post Training Self Efficacy $(\mathrm{N}=133)$

\begin{tabular}{|c|c|c|c|c|c|c|c|c|c|c|c|c|}
\hline \multirow{3}{*}{$\begin{array}{l}\text { Item: How confident } \\
\text { are you that: }\end{array}$} & & & & & \multicolumn{5}{|c|}{ Paired Differences } & \multirow{3}{*}{$t$} & \multirow{3}{*}{$d f$} & \multirow{3}{*}{$p$} \\
\hline & \multicolumn{2}{|c|}{$\stackrel{\text { Pre- }}{\underline{\text { Training }}}$} & \multicolumn{2}{|c|}{$\underline{\text { Post- }}$} & \multicolumn{5}{|c|}{$95 \% \mathrm{CI}$} & & & \\
\hline & $\mathrm{M}$ & $\mathrm{SD}$ & $\mathrm{M}$ & SD & M & SD & SEM & Lower & Upper & & & \\
\hline $\begin{array}{l}\text {...you understand } \\
\text { the challenges and } \\
\text { barriers facing } \\
\text { Dreamers students? }\end{array}$ & 2.40 & .98 & 3.87 & .67 & -1.50 & .80 & .07 & -1.64 & -1.37 & -21.58 & 132 & .000 \\
\hline $\begin{array}{l}\text {...you could refer a } \\
\text { Dreamer student who } \\
\text { approaches you for } \\
\text { support to appropriate } \\
\text { resources on campus? }\end{array}$ & 2.22 & 1.15 & 4.16 & .77 & -1.87 & 1.20 & .11 & -2.08 & -1.66 & -17.86 & 130 & .000 \\
\hline $\begin{array}{l}\text {...you would } \\
\text { know what to do } \\
\text { if immigration } \\
\text { enforcement (ICE) } \\
\text { officials came to } \\
\text { campus? }\end{array}$ & 1.67 & .96 & 4.17 & .74 & -2.53 & .93 & .08 & -2.70 & -2.37 & -31.17 & 130 & .000 \\
\hline
\end{tabular}


Table 2 cont'd

\begin{tabular}{|c|c|c|c|c|c|c|c|c|c|c|}
\hline \multirow{3}{*}{$\begin{array}{c}\text { Item: How confident } \\
\text { are you that: }\end{array}$} & \multirow[b]{2}{*}{ 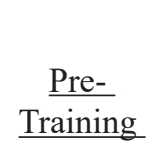 } & \multirow[b]{2}{*}{$\underline{\text { Post- }}$} & \multicolumn{5}{|c|}{ Paired Differences } & \multirow{2}{*}{$t$} & \multirow{2}{*}{$d f$} & \\
\hline & & & & & & & & & & $p$ \\
\hline & $\mathrm{M} \quad \mathrm{SD}$ & $\mathrm{M} \quad \mathrm{SD}$ & M & SD & SEM & Lower & Upper & & & \\
\hline
\end{tabular}

...you could carry

out an action plan to

support Dreamers

$\begin{array}{llllll}2.38 & 1.27 & 3.81 & .78 & -1.46 & 1.23\end{array}$

$.23 \quad .11$

$-1.67$

$-1.25$

$-13.57$

130

.000

students in your

department or unit?

...you can find

accurate resources

to learn more about

$\begin{array}{lllllll}2.89 & 1.16 & 4.18 & .80 & -1.32 & 1.19 & .10\end{array}$

.10

$-1.53$

$-1.12$

$-12.69$

130

.000

Dreamer students?

Note. Range for all items is 1-5.

\section{Satisfaction with Training}

Responses $(n=173)$ to the satisfaction with training items were relatively high across each assessed aspect (range 1-4): training content $(M=3.50, S D=.64)$, clarity of information $(M=3.43, S D=.68)$, pace of the training $(M=3.39, S D=.79)$, helpfulness of training $(M=3.57, S D=.62)$, and structure of training $(M=3.45, S D=.73)$. This indicates that those who completed the post-training survey were generally quite satisfied with each domain of the training.

\section{"What did you find most helpful about this training?"}

Twelve themes were derived from responses to this question. Responses varied significantly as evidenced in Table 1. The most frequent responses were about the helpfulness of the factual information provided in the information session, and working through the Dreamer student scenarios.

\section{"Are there any suggestions for improvement you'd like to share?"}

Seven themes were derived from responses to this question. Most often, participants provided very specific suggestions that did not lend themselves to subcategorization (e.g., speed up the check-in process). Another frequent theme was satisfaction with and praise for the training without any recommendations for change. The latter is exemplified by one participant's comment that they "really would not change a thing... very helpful, and one of the very most thoughtful university trainings in which I have participated." The third most frequent theme was focused on having more time for specific components of the training, such as time for networking with colleagues or for small group discussions of their action plans. Three of these recommendations argued for extending the four-hour time frame of the training.

\section{"Please briefly describe your pledge or action plan."}

Seven themes were derived from responses to this prompt. Many participants pledged to review their unit or department's eligibility criteria for financial aid and scholarships, to determine whether these could be more inclusive of Dreamer students. For example, one participant wrote: "I pledged to review university scholarships for eligibility and to create an info packet I can use to direct students to support should they share that they need it." A number of participants pledged to share information about what to do if ICE comes to campus with their colleagues; others planned to simply add the university's General Counsel contact 
information into their phones. Other participants pledged to make their unit or department website and other information more accessible and inclusive of Dreamer students, for instance, one participant reported their pledge to "review program website content to be sure its DREAMER friendly". Many participants pledged to post their Ally placard, once received, prominently in their office space, or to include a statement of support for Dreamer students in their email signatures. Finally, many participants pledged to inform their colleagues about future Ally trainings.

\section{Discussion}

The purpose of the present study was to describe and evaluate a Dreamer Ally training for faculty and staff at a large, public, research university. Our findings indicate that most participants sought the training in order to better support Dreamer students on campus. After the training, participants reported significantly higher self-efficacy related to supporting Dreamer students. Specifically, they were more confident in their understanding of Dreamer student challenges and barriers, in their knowledge of what to do if ICE officials came to campus, and in their abilities to refer Dreamer students to appropriate resources, to find accurate resources to continue learning about Dreamers, and to carry out action plans for supporting Dreamers. Participants also reported high levels of satisfaction with the training, with suggestions for improvement focused on minor shifts to content and format. Furthermore, participants completing the Ally training pledged to take a range of actions in order to support Dreamer students, including, most commonly: 1) reviewing eligibility criteria for unit- and university-level scholarships and financial aid to make these more inclusive of Dreamers; 2) visibly displaying support for Dreamer students using email signatures, syllabus language, and stickers and placards; and 3) committing to stay informed about the challenges facing Dreamer students and the resources available to support Dreamers on campus.

Responses to post-training surveys suggest broad variation in the portion of the training that participants found most helpful, with the didactic information session most frequently highlighted. Further, there were no clear trends in suggestions for improvement that would lead to making pedagogical changes in the intervention. We suspect that incorporating a variety of activities in the training- from lecture-style delivery of information, to empathy-building small group discussions, to hands-on problem-solving during the scenario portion of the training - was important to participants' high levels of satisfaction with the training.

\section{Implications}

Our Ally training intervention drew from similar efforts developed to raise awareness of challenges facing Dreamer students and build support systems on university and college campuses to ensure their success. Dreamer Ally trainings initiated in the 2010s have become more important as Federal policy changes have called in to question the future of DACA, and made other supports for immigrant students uncertain and precarious (DHS, 2020; Muñoz et al., 2018; Pierce, 2019). The present findings contribute to the small body of literature documenting the potential role of Dreamer Ally trainings in making U.S. university and college campuses more undocu-friendly, that is, supportive of the academic and success and wellbeing of Dreamer students (Cadenas et al., 2016; Chen \& Rhoads, 2016; Cisneros \& Cadenas, 2017; Cisneros \& Lopez, 2020; Suárez-Orozco et al., 2015).

Ally training participants in the present study expressed much higher levels of self-efficacy related to their ability to support Dreamer students after the training intervention. Given the relationship between self-efficacy and behavior (Bandura, 1986), these findings are promising for using Dreamer Ally interventions targeting faculty and staff as a means of working towards broader institutional-level changes on university campuses. 
Faculty and staff who provide critical information and resources to undocumented students have been described as "institutional empowerment agents" (Southern, 2016, p. 308). Those allies who work within their institutions to challenge inequities and promote critical changes that enhance the wellbeing of undocumented students may engage in "transformative resistance" (Chen \& Rhoads, 2016, p. 520). Our intervention aimed to increase the number of institutional empowerment agents on campus, stimulate transformative resistance by translating participants' newfound knowledge and self-efficacy into action plans, and make the university campus more undocu-friendly (Abrego, 2006; Suárez-Orozco, Katsiafikas et al., 2015). Although our study design did not include follow up with participants regarding implementation of their action plans, as members of the DWG and of the campus community, we have observed and heard of many programmatic and departmentlevel changes made by Ally training participants. For instance, participants have spearheaded efforts to review scholarship eligibility criteria and have removed citizenship requirements wherever possible. Across campus, and especially in the University financial aid and admissions offices, it appears that staff participation in the Ally training has resulted in greater awareness of resources for Dreamers, and information about these resources is more prominently displayed on unit websites. More anecdotally, the Dreamer Ally placards given to participants upon completion of the training are now prominently displayed across many campus departments and offices, offering visible signs of support and inclusion.

In addition to these changes fostered by participants, the coordination of successful and highly-attended (including university administrators) Ally trainings has added impetus to the University administration to dedicate greater resources to Dreamer students. For instance, with institutional support, the DWG was able to initiate a Dreamer scholarship for the first time in the 2018-19 academic year. Additionally, the University administration made additional resource commitments to fund a Dreamer student support coordinator and a part-time administrative support position for the DWG. Concurrently, the campus mental health center added two Latinx specialist positions, including one dedicated to undocumented students. These changes cannot be attributed to the Ally trainings, but it is clear that the trainings raised the profile of the DWG on campus, and enhanced institutional impetus for supporting Dreamer students.

As part of our ongoing work, the DWG continues to promote activities other than the Ally trainings in order to foster an undocu-friendly campus climate at the institutional level. For example, many faculty and staff members want members of their unit to have more information about Dreamers, but do not believe their peers can or will commit to a four-hour training. As such, DWG members continue to voluntarily offer the information session as a one-hour presentation to campus units, departments, and within courses. Hundreds of faculty, staff and students have participated in these "Information Sessions," including academic departments, the graduate school, the office of admissions, the career center, and the mental health center. A Dreamer student advisory board has been formed, and facilitates communication of Dreamer student concerns and goals and aid in coordinating resources to promote Dreamer health and wellbeing (Burdette et al., 2019). All of these steps have contributed to making our campus more undocu-friendly (Suárez-Orozco, Katsiafikas et al., 2015). That said, continuing to work with Dreamer students and prioritize and visibilize their needs on campus, including financial and legal assistance, academic advising, and mental health supports, remains a priority.

There are many transformations that need to take place in order to make university campuses such as ours more undocu-friendly. Access to legal assistance and financial support, institutional statements affirming the belonging and inclusion of Dreamer students, and plans for supporting and protecting students in the event of the elimination of DACA, TPS protection, and other policy changes adverse to their academic success and overall wellbeing, are also critical. Along these lines, the DWG has encouraged our University Administration to participate in national-level advocacy work around the continuation of DACA and access to higher education for undocumented students more broadly. Our DWG also engages with the University's state legislative liaison, encouraging policies such as the continuation and expansion of the state's tuition equity program. University 
administrators can implement equity practices, such as more inclusive admissions or financial aid policies, even in the absence of longer term federal or state policy changes (Barnhardt et al. 2017; Mwangi et al., 2019).

\section{Limitations}

The use of a one group pre-post test design precludes making causal assumptions about the effects of this intervention. The addition of a control group, and a longitudinal design with follow up assessments of self-efficacy and implementation of action plans, would provide a stronger test of the intervention. Assessing participant impressions of the training after a longer time interval might yield more suggestions for improving its utility and effectiveness. In addition, although participants were provided with multiple reminders to complete the pre and post survey, many opted not to do so. This limits generalizability of the findings. Our follow up analyses indicated that those who completed only a pre or a post survey did not differ in pre or post test self-efficacy, respectively, from those who completed both pre and post measures. This increases our confidence in the findings for self-efficacy. It is possible, however, that participants who were very dissatisfied with the training simply did not respond to the follow up survey.

Another limitation to generalizability is that participants self-selected into the training, suggesting they were motivated to support Dreamer students. While there was no overt resistance to the content of the training evidenced in participants' survey responses, the voluntary nature of the training means our findings are not generalizable to all university faculty and staff. Along these lines, one of our study participants advocated for more overt focus on mandatory employee involvement in such efforts, noting:

"It would have been helpful to have more of an opportunity to discuss how/ why supporting dreamers is in line with our job responsibilities/ mission/ vision/ values. Maybe there just seemed to be an assumption that everyone in attendance was 'on board' with supporting dreamer students. I think some reminders, or discussion about how our support of dreamer students is not purely a personal political decision, but may indeed be a responsibility as an employee of [institution]."

It seems likely that faculty and staff with attitudes counter to the support and inclusion of Dreamer students would not participate in a voluntary training. If trainings were to be institutionalized and required of all or new employees, it would be important to incorporate more explicit attention to employee roles, rights, and responsibilities relative to Dreamer students. Further, it may be important to address more explicitly the larger historical and legislative factors that guarantee the continued presence of undocumented students, as well as how attitudes may be shaped by racial and citizenship privilege (Abrego, 2019; Patler, 2018).

Finally, a broader limitation of this study is that Ally trainings of this sort do not address the ecological levels of federal policy and the larger climate that combine to limit students' opportunities for adjusting their status (becoming LPRs or citizens). So long as there remain a large group of undocumented students in our colleges and universities, as staff and faculty committed to serving all students, we will need to continue to find ways to support these students, within existing political limitations. As staff and faculty at a public university, we have had to be very careful not to endorse particular political party platforms, and focus instead on services and resources effecting students. This is sometimes a fine tightrope to walk, as students express concern about specific political decisions (e.g. the DACA rescission) and the impact of these on their academic security and future success.

\section{Summary and conclusion}

We described and evaluated a voluntary four-hour Dreamer Ally training to faculty and staff at our large public university. The training was positively received by the faculty and staff who responded to our follow up survey. Participants were satisfied with the content, clarity, pace, helpfulness, and structure of the training, and suggestions for improvement did not yield any problematic aspects of the training. The most helpful 
components of the training were the information session and the scenarios. Participants committed to a variety of actions to improve inclusion and support of Dreamer students, and anecdotal evidence suggests that many of these actions have been taken. The need for Dreamer Ally trainings may grow substantially in the coming years in light of both large numbers of undocumented and Dreamer university and college students, and continuing policy uncertainties surrounding their possibilities for permanent authorized status and/or U.S. citizenship.

\section{Authors Note:}

The authors wish to acknowledge all members of the Dreamers Working Group for their collective commitment to developing and implementing the ally trainings, and all ally training participants for their commitments to supporting Dreamer students.

\section{Corresponding Author}

Ellen Hawley McWhirter, Ph.D.

Ann Swindells Professor in Counseling Psychology

Counseling Psychology \& Human Services

5251 University of Oregon

Eugene OR 97403-5251

ellenmcw@uoregon.edu

(541) 346-2443 


\section{References}

Abrego, L. J. (2006). “I can’t go to college because I don’t have papers": Incorporation patterns of Latino undocumented youth. Latino Studies, 4(3), 212-231.

Abrego, L. J. (2019). Relational legal consciousness of US citizenship: Privilege, responsibility, guilt, and love in Latino mixed-status families. Law \& Society Review, 53(3), 641-670.

Abrego, L. J., \& Gonzales, R. G. (2010). Blocked paths, uncertain futures: The postsecondary education and labor market prospects of undocumented Latino youth. Journal of Education for Students Placed at Risk, 15(1-2), 144-157.

Bandura, A. (1986). The explanatory and predictive scope of self-efficacy theory. Journal of social and clinical psychology, 4(3), 359-373.

Bandura, A. (2001). Guide for constructing self-efficacy scales (revised). Retrieved from http://www.emory. edu/EDUCATION/mfp/banduraguide.html

Barnhardt, C. L., Phillips, C. W., Young, R. L., \& Sheets, J. E. (2017). The administration of diversity and equity on campuses and its relationships to serving undocumented immigrant students. Journal of Diversity in Higher Education, 10(1), 1-10.

Braun, V. \& Clarke, V. (2006) Using thematic analysis in psychology. Qualitative Research in Psychology, 3(2), 77-101.

Broido, E. M. (2000). The development of social justice allies during college: A phenomenological investigation. Journal of College Student Development, 41(1), 3-18.

Bronfenbrenner, U. (1979). The ecology of human development. Cambridge, MA: Harvard University Press.

Burdette, A., Chavez, E., Diouf, M., Getrich, C., Leiva, D., Leiva, K., \& Ortez-Rivera, A. (2019). The Dacamented Dream Team: Guiding research and building social support amidst immigrant-related uncertainty. Practicing Anthropology, 41(2), 8-16.

Cadenas, G. A., Cisneros, J., Todd, N. R., \& Spanierman, L. B. (2018). DREAMzone: Testing two vicarious contact interventions to improve attitudes toward undocumented immigrants. Journal of Diversity in Higher Education, 11(3), 295-308.

Caicedo, D. A. (2019). DREAMers and values: An urban and suburban community college comparison. Journal of Diversity in Higher Education, 12(4), 319-329.

Capps, R., Fix, M., \& Zong, J. (2016). A profile of US children with unauthorized immigrant parents. Washington, DC: Migration Policy Institute.

Cebreros, A. (2016). It's definitely our success: Children of undocumented immigrants in higher education. Masters Thesis, University of Oregon. https://scholarsbank.uoregon.edu/xmlui/handle/1794/20526

Center for American Progress (2019). What we know about DACA recipients, by state. https://www. americanprogress.org/issues/immigration/news/2019/09/12/474422/know-daca-recipients-state/

Chen, A. C. R., \& Rhoads, R. A. (2016). Undocumented student allies and transformative resistance: An ethnographic case study. The Review of Higher Education, 39(4), 515-542.

Cisneros, J., \& Cadenas, G. (2017). DREAMer-ally competency and self-efficacy: Developing higher education staff and measuring lasting outcomes. Journal of Student Affairs Research and Practice, 54(2), 189-203.

Cisneros, J., \& Lopez, A. (2016). DREAMzone: Educating counselors and human service professionals working with undocumented students. Journal for Social Action in Counseling \& Psychology, 8(2), 3248 . 
Cisneros, J., \& Lopez, A. (2020). Ally competency and self-efficacy for working with undocumented students. Journal of Student Affairs Research and Practice, 57(3), 309-321. DOI: 10.1080/19496591.2019.1634464

Dash, G. F. (2020). Ethical considerations in providing psychological services to unaccompanied immigrant children. Ethics \& Behavior, 30(2), 83-96.

Department of Homeland Security (July 28, 2020). Department of Homeland Security will reject initial requests for DACA as it weighs future of the program. Retrieved from https://www.dhs.gov/ news/2020/07/28/department-homeland-security-will-reject-initial-requests-daca-it-weighs-future.

Enriquez, L.E., Hernandez, M.M., \& Ro, A. (2018). Deconstructing immigrant illegality: A mixed-methods investigation of stress and health among undocumented college students. Race and Social Problems, 10(3), 193-208.

Evans, N.J. \& Wall, V.A. (1991). Beyond tolerance: Gays, lesbians, and bisexuals on campus. Alexandria, VA: American College Personnel Association.

Fortuny, K., Capps, R., \& Passel, J. (2007). The characteristics of unauthorized immigrants in California, Los Angeles County, and the United States (Research Report). Washington, D.C: The Urban Institute.

Gemignani, M., \& Hernandez-Albujar, Y. (2015). Hate groups targeting unauthorized immigrants in the US: discourses, narratives and subjectivation practices on their websites. Ethnic and Racial Studies, 38(15), 2754-2770.

Gonzales, R. G. (2016). Lives in limbo: Undocumented and coming of age in America. Oakland: University of California Press.

Gurrola, M., Ayón, C., \& Salas, L.M. (2016). Mexican Adolescents' education and hopes in an anti-immigrant environment: the perspectives of first-and second-generation youth and parents. Journal of Family Issues, 37(4), 494-519.

McHugh, M. (2018). In the age of Trump: Populist backlash and progressive resistance create divergent state immigrant integration contexts. Washington, DC: Migration Policy Institute.

Muñoz, S. M., Vigil, D., Jach, E. M., \& Rodriguez-Gutierrez, M. M. (2018). Unpacking resilience and trauma: Examining the "Trump effect" in higher education for undocumented Latinx college students. Association of Mexican American Educators Journal, 12(3), 33-52.

Mwangi, C. A. G., Latafat, S., Thampikutty, C., \& Van, J. (2019). Examining university responses to the DACA rescission: A critical discourse analysis. Innovative Higher Education, 44(4), 249-265.

Nienhusser, H. K., \& Espino, M. M. (2017). Incorporating undocumented/DACAmented status competency into higher education institutional agents' practice. Journal of Student Affairs Research and Practice, 54(1), 1-14.

Nienhusser, H. K., \& Oshio, T. (2020). Postsecondary education access (im) possibilities for undocu/ DACAmented youth living with the potential elimination of DACA. Educational Studies, 1-23. https:// doi.org/10.1080/00131946.2020.1757448

Patler, C. (2018). Citizen advantage, undocumented disadvantage, or both? The comparative educational outcomes of second and 1.5-generation Latino young adults. International Migration Review, 52(4), 1080-1110. DOI: 10.1111/imre.12347

Pierce, S. (2019, May). Immigration-related policy changes in the first two years of the Trump administration. Washington, DC: Migration Policy Institute. 
Pierce, S., Bolter, J., \& Selee, A. (2018). US immigration policy under Trump: Deep changes and lasting impacts. Washington, DC: Migration Policy Institute.

Pierce, S., \& Selee, A. (2017). Immigration under Trump: A review of policy shifts in the year since the election. Washington, DC: Migration Policy Institute.

Roche, K. M., Vaquera, E., White, R. M., \& Rivera, M. I. (2018). Impacts of immigration actions and news and the psychological distress of US Latino parents raising adolescents. Journal of Adolescent Health, 62(5), 525-531.

Sanchez, R. E. C., \& So, M. L. (2015). UC Berkeley's undocumented student program: Holistic strategies for undocumented student equitable success across higher education. Harvard Educational Review, 85(3), 464-477.

Segal, E. A., \& Wagaman, M. A. (2017). Social empathy as a framework for teaching social justice. Journal of Social Work Education, 53(2), 201-211.

Southern, K. G. (2016). Institutionalizing support services for undocumented students at four-year colleges and universities. Journal of Student Affairs Research and Practice, 53(3), 305-318.

Suárez-Orozco, C., Katsiaficas, D., Birchall, O., Alcantar, C. M., Hernandez, E., Garcia, Y., ... \& Teranishi, R. T. (2015). Undocumented undergraduates on college campuses: Understanding their challenges and assets and what it takes to make an undocufriendly campus. Harvard Educational Review, 85(3), 427463.

Suárez-Orozco, M.M., Teranishi, R., \& Suárez-Orozco, C.E. (2015). In the shadows of the ivory tower: Undocumented undergraduates and the liminal state of immigration reform. UCLA. Retrieved from https://escholarship.org/uc/item/2hq679z4

TheDream.US. (n.d.). UndocuAlly training pre-work research activity and readings. Retrieved from https:// TheDream.US.

United We Dream (n.d.). Retrieved from http://unitedwedream.org/wp-content/uploads/2015/01/UWDN InstitutionalToolKit final-1.pdf

U.S. Census Bureau (2017). Annual Estimates of the Resident Population by Sex, Race, and Hispanic Origin for the United States, States, and Counties: April 1, 2010 to July 1, 2016. PEPSR6H, Release Date: June 2017; Retrieved from www.census.gov.

U.S. Citizenship \& Immigration Services (n.d.) Temporary protected status. Retrieved from https://www.uscis. gov/humanitarian/temporary-protected-status.

Warren, R., \& Warren, J. R. (2013). Unauthorized Immigration to the United States: Annual estimates and components of change, by state, 1990 to 2010. International Migration Review, 47(2), 296-329. doi:10.1111/imre.12022

Yasuike, A. (2019) The academic success of undocumented Latino students: School programs, nonprofit organizations, and social capital. Journal of Latinos and Education, 18(1), 42-52. DOI: 10.1080/15348431.2017.1418354

Zong, J., \& Batalova, J. (2019). How many unauthorized immigrants graduate from U.S. High Schools annually? Washington, DC: Migration Policy Institute. 